\title{
Psychological distress in the COVID-19 pandemic: prevalence and associated factors at a nursing college
}

\author{
Sofrimento psíquico na pandemia de COVID-19: prevalência e fatores associados em uma faculdade de enfermagem
}

Sufrimiento psicológico en la pandemia de COVID-19: prevalencia y factores asociados en una facultad de enfermería

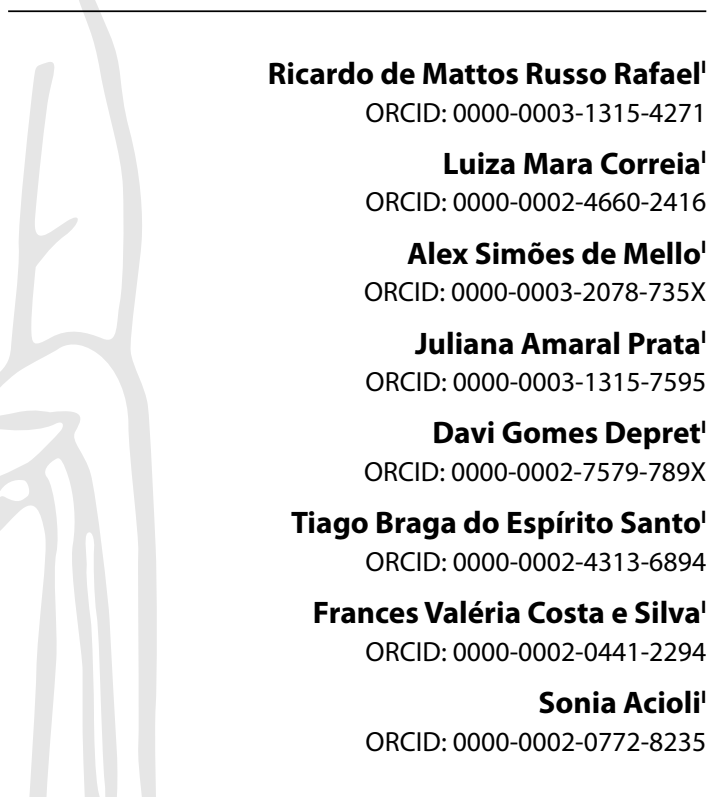

'Universidade do Estado do Rio de Janeiro. Rio de Janeiro, Rio de Janeiro, Brazil.

How to cite this article: Rafael RMRR, Correia LM, Mello AS, Prata JA, Depret DG, Espirito-Santo TB, et al. Psychological distress in the COVID-19 pandemic: prevalence and

associated factors at a nursing college. Rev Bras Enferm. 2021;74(Suppl 1):e20210023. https://doi.org/10.1590/0034-7167-2021-0023

Corresponding author: Ricardo de Mattos Russo Rafael E-mail: prof.ricardomattos@gmail.com

EDITOR IN CHIEF: Dulce Barbosa ASSOCIATE EDITOR: Álvaro Sousa

Submission: $01-26-2021$

Approval: 04-02-2021

\section{ABSTRACT}

Objective: to analyze the prevalence and factors associated with psychological distress in students and workers at a public nursing college during the COVID-19 pandemic. Methods: this is a cross-sectional study, carried out by a structured survey based on the internet with a sample of 477 students and workers. Prevalence ratios were calculated and adjusted Prevalence Ratios were obtained by Poisson Regression, with robust variance control and stepwise backward technique. Results: the prevalence of psychological distress was $19.29 \%$ (95\%Cl: 15.98-23.09). Testing (PR 1.55; p-value 0.026) and belonging to the COVID-19 risk group (1.71; $p$-value 0.005$)$, perception of family atmosphere (PR 3.10; $p$-value $<0.001)$, feelings of loneliness (PR 2.64; p-value $<0.001$ ) and family violence (PR 2.21; p-value 0.005 ) were associated with distress. Conclusions: the high magnitude of the event and its association with COVID-19, loneliness and family dynamics arouse the need to build strategies that promote a place of protection for schools.

Descriptors: Nursing; Students, Nursing; Psychological Distress; Pandemics; Coronavirus Infections.

\section{RESUMO}

Objetivo: analisar a prevalência e os fatores associados ao sofrimento psíquico em estudantes e trabalhadores de uma faculdade pública de enfermagem durante a pandemia de COVID-19. Métodos: estudo transversal, realizado por inquérito estruturado baseado na internet com amostra de 477 estudantes e trabalhadores. Foram calculadas prevalências e as Razões de Prevalência ajustadas foram obtidas por Regressão de Poisson, com controle de variância robusta e técnica stepwise backward. Resultados: a prevalência de sofrimento psíquico foi 19,29\% (IC95\%:15,98-23,09). A testagem (RP 1,55;p-valor 0,026) e pertencimento ao grupo de risco $(1,71 ; p$-valor 0,005$)$ da COVID-19, percepção da atmosfera familiar (RP 3,10;p-valor $<0,001$ ), sentimentos de solidão (RP 2,64; -valor $<0,001$ ) e violência familiar (RP 2,21;p-valor $0,005)$ se associaram ao sofrimento. Conclusões: a elevada magnitude do evento e sua associação com a COVID-19, a solidão e a dinâmica familiar despertam a necessidade de construção de estratégias que promovam um lugar de proteção pelas escolas.

Descritores: Enfermagem; Estudantes de Enfermagem; Angústia Psicológica; Pandemias; Infecções por Coronavírus.

\section{RESUMEN}

Objetivo: analizar la prevalencia y los factores asociados al malestar psicológico en estudiantes y trabajadores de una facultad pública de enfermería durante la pandemia de COVID-19. Métodos: estudio transversal, realizado mediante una encuesta estructurada basada en internet con una muestra de 477 estudiantes y trabajadores. Se calcularon las razones de prevalencia y se obtuvieron las razones de prevalencia ajustadas mediante Regresión de Poisson, con control de varianza robusto y técnica stepwise backward. Resultados: la prevalencia de distrés psicológico fue de 19,29\% (IC 95\%: 15,98-23,09). Prueba (RP 1,55; p-value $0,026)$ y pertenencia al grupo de riesgo $(1,71 ; p$-value 0,005$)$ de COVID-19, percepción del ambiente familiar (RP 3,10; $p$-value $<0,001$ ), sentimientos de soledad (RP 2,64; $p$-value $<0,001$ ) y la violencia familiar (RP 2,21; $p$-value 0,005 ) se asociaron con el sufrimiento. Conclusiones: la alta magnitud del evento y su asociación con COVID-19, la soledad y la dinámica familiar despiertan la necesidad de construir estrategias que promuevan un lugar de protección para las escuelas.

Descriptores: Enfermería; Estudiantes de Enfermería; Distrés Psicológico; Pandemias; Infecciones por Coronavirus. 


\section{INTRODUCTION}

The need for the world population to adapt to the recommended measures to contain COVID -19, declared a pandemic in March 2020, brought strong repercussions to the field of mental health. The absence of immunizers and effective treatments to fight infection, added to the volume of cases and deaths from the disease, resulted in the need to adopt measures of physical and social distance to contain the progression of the disease ${ }^{(1)}$. The advance of the pandemic in American countries found unstable political and economic conditions, strained regional and international relations and weakened health systems $s^{(2)}$. In the case of Brazil, a country of continental territorial proportions, the situation was even more challenging, due to the low investment in public policies, which has culminated in the accentuation of social and health inequalities ${ }^{(1-2)}$.

In this context, it is considered that the restrictive strategies of circulation and agglomeration of people, although necessary in the sanitary perspective, interfere in the territorial clinic approach recommended by mental health. For this field, the notion of territory goes beyond the simple spatial delimitation, constituting itself as a space for production of life, with objective and subjective dimensions that affect people's and communities' relational dynamics and psychological health ${ }^{(3)}$.

From this perspective, the negative impacts of the pandemic on mental health are evidenced by an increase in distress experiences, expressed in anxiety, anger, confusion and common mental disorders (CMD), which may involve depression, insomnia, difficulties in concentrating, irritability, somatic complaints, fatigue and feelings of worthlessness ${ }^{(4-5)}$. Thus, CMDs have repercussions on social and labor relations, quality of life and the performance of daily activities, arising from the state of psychological distress ${ }^{(6)}$.

Of varying conceptualization and complex delimitation, psychological distress is a phenomenon recorded in history and that commonly appears in the form of diseases, disorders, mental disorders and even madness, accompanied by labels that produce stigmas and enhance distress ${ }^{(7)}$. Psychological distress is inherent to the condition of humanity; however, it demands care when this experience compromises individuals' lives and causes somatic diseases.

Due to its association with individual singularities and for its non-specific characteristic, psychological distress is difficult to measure, which makes it difficult for health professionals to identify it. Among other issues, such distress is related to destabilizing situations and emotional distress, which are manifested through feelings of sadness, frustration, helplessness and incapacity, being compatible with $\mathrm{CMDs}^{(8)}$.

The expanded understanding of mental health seizes subjects' centrality in the care process, thus moving away from the focus on psychiatric diagnosis and disease as factors that validate people's existence-distress, worrying about the experiences and their impacts, objectives and subjective on the context of life in society. This view, in addition to a theoretical perspective, is capable of reorienting care in the field of health, more specifically mental health ${ }^{(9)}$.

Therefore, unrelated to psychiatric nosography, the study of psychodynamics understands psychological distress as the expression of feelings associated with negative experiences of existence that harm the person's relationship with the world ${ }^{(8)}$. In this sense, the term "psychological distress" encompasses CMD, but escapes diagnostic limits, as it sees distress and individual needs as central objects of care.

In addition to distress potentially produced by a health emergency of worldwide proportions such as COVID-19, the feeling of loneliness arising from the physical-social distance is also an aspect that deserves to be studied. Although loneliness is understood as a common experience for people, the event has proved to be an important predictor of psychological distress, especially linked to depressive and anxiety syndromes ${ }^{(10-11)}$. The profusion of negative feelings arising from the physical-social distance, added to the uncertainties regarding the diagnosis of COVID-19, are elements that can affect people's physical, psychological health and social relationships ${ }^{(12)}$.

Although current literature is already growing in relation to psychological distress in the pandemic of COVID-19, ${ }^{(4-5)}$ there is still an important gap in the behavior of this phenomenon in academic communities. It is important to consider that, even before the interruption of face-to-face classes in schools and universities, health training institutions, as in the case of nursing colleges, are invariably involved in facing the pandemic in Brazil and in the world, leaving the need to better recognize the phenomenon of distress in this context. In this regard, the study raises the following research question: what is the prevalence and what are the factors associated with psychological distress in students and workers at a public nursing college during the COVID-19 pandemic period?

\section{OBJECTIVE}

To analyze the prevalence and factors associated with psychological distress in students and workers at a public nursing college during the COVID-19 pandemic.

\section{METHODS}

\section{Ethical aspects}

This study was approved by the Institutional Review Board of Universidade do Estado do Rio de Janeiro. The ethical precepts of voluntary and consented participation of each participant were respected, according to Resolution 466/2012 of the Brazilian National Health Council (Conselho Nacional de Saúde).

\section{Study design, period, and place}

This is a sectional study of a research baseline entitled "Pandemia de COVID-19 e vida acadêmica: coorte sobre a situação da doença, condições sociais e experiências acadêmicas". Due to the COVID-19 pandemic and the interruption of face-to-face activities in schools and universities, an internet-based cohort (E-Survey) was designed, in which the subset of data collected from June 4 to September 32020 was analyzed in this manuscript. For the communication of results, the composition of this article followed the Strengthening the Reporting of Observational Studies in 
Epidemiology (STROBE) ${ }^{(13)}$ and the Checklist for Reporting Results of Internet E-Surveys (CHERRIES) guidelines ${ }^{(14)}$. The study was conducted at a public nursing college in the state of Rio de Janeiro, whose training programs are developed at the undergraduate, lato sensu graduate levels, including 14 residency programs, in addition to master's and doctoral degrees.

\section{Study population}

The target population of this investigation constituted the college's entire academic community, totaling 954 potential participants, being 326 undergraduate students; 410 students of lato sensu graduate courses, 88 graduate students (master's and doctoral level), 104 college members and 26 administrative staff. With the convenience sampling technique, the entire community with an active link at the time of data collection was eligible to participate in the investigation. This manuscript adopted as exclusion criteria participants who did not respond to the item corresponding to the study's outcome such as psychological distress.

Subject recruitment took place in two phases. In the first phase of collection, an invitation letter containing the research objectives and procedures, a link to the electronic questionnaire and the Informed Consent Form were sent by email. For unanswered cases, with consent or not to participate, a new email was sent after three days. In the absence of contact, the second phase, telephone contact, began, maintaining the three-day intervals between attempts. In this phase, resources were used to send messages and calls, mainly because it understands that some subjects might not have access to the internet. In cases where both attempts were unsuccessful, a third email was used. The cases of non-response in the recruitment phases were considered losses.

\section{Study protocol}

A pilot study with 30 participants was carried out in June 2020 , before the collection period. The pilot study group was composed of students from all levels of education, professors and administrative staff, with the purpose of testing the dynamics of data collection and solving problems of interpretation on the instrument items. After the adjustments indicated by the pilot study, the final instrument consisted of 136 items, 80 of which are mandatory items and 27 electronic form screens.

In order to meet the proposed objective, this manuscript has psychological distress as its outcome variable, measured by a single item, "Do you feel you are in distress or in need of professional support?", With a binary answer option (No/Yes). As it is a non-mandatory item in the data collection instrument, not all research participants answered this question. The study covariables were treated in three modules: sociodemographic characteristics, clinical characteristics and characteristics of social distance and the home environment.

The measurement of sociodemographic characteristics occurred by "age group", measured as a numerical variable and transformed into categorical (age groups), color/ethnicity, gender, sexual orientation, functional category in the institution and work in the front line. It is noteworthy that, due to the small sample of trans people $(n=1)$ and the absence of other gender identities in the recruited group, the variable was recategorized as "woman" and "man". The functional category was assessed with multiple responses according to respondents' level of training and work, but recategorized as professor, administrative technician, undergraduate students, lato sensu (specialization programs) and stricto sensu (master's and doctoral programs) graduate students. Was the work on the front line measured by the item "By a nursing college and/or outside it, are you on the front line of action in the pandemic (health care, cleaning, public assistance, etc.)? with binary response (No/Yes).

The clinical characteristics mapped the situation of a risk group for COVID-19, a family member in a risk group, testing and positive result for the disease, positive history with home contact, positive history of clinical manifestation of flu-like syndrome (FLS) and Severe Acute Respiratory Syndrome (SARS).

Testing and positive result for the disease were seized through items that questioned the test performance, the type of test performed and its result."Risk group" was composed of at least one positive answer for diagnoses of pregnancy, postpartum, obesity, and chronic diseases (heart diseases, diabetes, liver diseases, neuropathies, immunodeficiencies, nephropathies, cancer and chronic respiratory diseases), in addition to the classification "over 60 years" using "age group". The "family member at risk" group was assessed using the "Do any family members who live with you have any of the diseases previously reported?" item.

Positive history of clinical manifestations of respiratory syndromes followed the case definitions proposed by the Ministry of Health, considering FLS when two or more of the following characteristics are present: fever $\left(37.8^{\circ} \mathrm{C}\right)$, fever sensation, sore throat, headache, cough, coryza and olfactory and taste losses ${ }^{(15)}$. A positive history of SARS was considered when positive for FLS with at least one of the following markers: dyspnea or respiratory distress with persistent pressure in the chest, oxygen saturation below $95 \%$ in ambient air, or cyanosis.

Finally, the last characteristics module aimed to map four variables that are potentially predictive of social distance and characteristics of the home and family environment. Serving as a marker of social distance, "received/made visits" was considered positive when present in one of the two measurement items: "Are you going to the home of relatives and/or friends?" and "Are you receiving relatives and/or friends at home?".

Family atmosphere, understood here as a general assessment of the place one lives, was seized through the "How do you assess the environment that you have lived in this period of social detachment (in the pandemic)?" item, having as response categories: "great"; "well"; "regular"; "bad"; "very bad"; "I do not know"; "I do not want to answer". Treatment of responses followed aggregation of "good" and "bad" classifications in a single category as well as the "regular","bad" and "very bad" answers. For the cases of "I don't know" and "I don't want to answer", missing data were considered.

The history of family violence and current family violence were seized by the items "I have experienced violence in my home environment in periods prior to the pandemic" and "In the period of social detachment (during the pandemic), I suffered violence in my home environment". In both items, the pattern of 
responses followed an ordinal scale with five categories, ranging from totally agree to totally disagree. "Neither agree nor disagree" answers were considered as missing data. When considering that the measurement of situations of violence can, by itself, only generate psychological distress to respondents, the item was not considered mandatory in the data collection instrument. When this occurred, data analysis considered as missing data as well as the answers "I neither agree nor disagree".

Finally, this module also measured feelings of loneliness through the Brazilian Scale of Solitude, cross-culturally adapted and validated for use in Brazil ${ }^{(16)}$. Adopting the cutoff points proposed by Barroso, Andrade \& Oliveira ${ }^{(17)}$, the interval from 0 to 22 points of the score was considered as minimal loneliness; as mild, between 23 and 35 points; as moderate, between 36 and 47; as intense, when it reached between 48 and 60 points. This manuscript uses the "minimal/mild" and "moderate/intense".

\section{Data analysis and treatment}

For database analysis and processing procedures, Stata SE 15 was used. The prevalence and $95 \%$ confidence interval $(95 \% \mathrm{Cl})$ of the study outcome were calculated, in addition to covariable distribution. Bivariate analyzes were carried out by means of crude Prevalence Ratios (PR) and $95 \% \mathrm{Cl}$, applying the chi-square test. Considering the binary outcome, all variables with $p$ value $<0.30$ in bivariate analyzes integrated the initial regression model, with the aim of verifying the factors associated with psychological distress. By means of Poisson Regression with robust variance control and applying the manual stepwise backward technique, the final model was built when all variables present presented $p$ value $<0.05$, resulting in adjusted PR.

\section{RESULTS}

Of the 954 subjects eligible for the study, 498 responded to the electronic questionnaires at the baseline of the cohort, making up the response rate of $52.20 \%$. Of these, 21 (4.22\%) were excluded because they did not answer the instrument item that corresponded to the study outcome. Thus, the final sample analyzed was 477 participants. The prevalence of psychological distress was 19.29\% (95\%Cl: 15.98 - 23.09).

Table 1 shows the distribution and crude PR of sociodemographic variables as a function of psychological distress. With the exception of the 30 to 39 age group and the functional categories of undergraduate and stricto sensu graduate students, there were no statistically significant differences between the prevalence by population subgroup. Color/ethnicity and sexual orientation are also among those with a $p$ value lower than the cut-off point of 0.30 and, therefore, were admitted in the final regression model.

The distribution and crude PR among the clinical characteristics associated with COVID-19 and psychological distress are presented in Table 2. Having presented clinical manifestation compatible with FLS presented a reducing effect of the prevalence of suffering in 38\% ( $p$ value 0.014 ), being the only variable with statistically significant difference in this subset. However, with the exception of the history of positive contact with COVID-19 cases ( $p$ value $0.545)$, all variables were introduced in the final regression model.
Table 1 - Distribution of variables and crude prevalence ratio of sociodemographic characteristics as a function of self-report of psychological distress in the academic community of a public nursing college from June 4 to September 3, 2020, Rio de Janeiro, Brazil, 2020 ( $N=477)$

\begin{tabular}{|c|c|c|c|c|}
\hline Variables & $\mathbf{n}$ & n (\%) & PR $(95 \% \mathrm{Cl})$ & $\begin{array}{c}p \\
\text { value }\end{array}$ \\
\hline Age group & 477 & & & \\
\hline From 18 to 19 years old & 302 & $69(22.85)$ & Reference & - \\
\hline From 30 to 39 years old & 91 & $11(12.09)$ & $0.53(0.29-0.96)$ & 0.035 \\
\hline From 40 to 49 years old & 42 & $6(14.29)$ & $0.62(0.29-1.35)$ & 0.232 \\
\hline 50 to 59 years old & 25 & $4(16.00)$ & $0.70(0.28-1.76)$ & 0.449 \\
\hline 60 years and older & 17 & $2(11.76)$ & $0.51(0.14-1.93)$ & 0.324 \\
\hline Color/ethnicity & 476 & & & \\
\hline Black/brown & 230 & $50(27.74)$ & Reference & - \\
\hline White & 241 & $41(17.01)$ & $0.78(0.54-1.13)$ & 0.196 \\
\hline Yellow/indigenous & 5 & $1(20.00)$ & $0.92(0.15-5.41)$ & 0.927 \\
\hline Sex & 477 & & & \\
\hline Women & 426 & $85(19.95)$ & Reference & - \\
\hline Men & 51 & $7(13.73)$ & $0.69(0.34-1.40)$ & 0.305 \\
\hline Sexual orientation & 462 & & & \\
\hline Heterosexuality & 413 & $74(17.92)$ & Reference & - \\
\hline Bisexuality & 28 & $5(17.86)$ & $0.99(0.44-2.27)$ & 0.994 \\
\hline Homosexual & 21 & $6(28.57)$ & $1.59(0.78-3.24)$ & 0.196 \\
\hline Functional category & 477 & & & \\
\hline Professor & 84 & $10(11.90)$ & Reference & - \\
\hline Administrative technician & 16 & $3(18.75)$ & $1.57(0.49-5.10)$ & 0.499 \\
\hline $\begin{array}{l}\text { Stricto sensu graduate } \\
\text { student }\end{array}$ & 31 & $9(29.03)$ & $2.44(1.09-5.44)$ & 0.029 \\
\hline Lato sensu graduate student & 112 & $14(2.50)$ & $1.04(0.49-2.25)$ & 0.900 \\
\hline Undergraduate student & 234 & $56(23.93)$ & $2.01(1.07-3.76)$ & 0.029 \\
\hline Work in the front line & 477 & & & \\
\hline No & 333 & $66(19.82)$ & Reference & - \\
\hline Yes & 144 & $26(18.06)$ & $0.91(0.60-1.37)$ & 0.656 \\
\hline
\end{tabular}

Table 2 - Distribution and crude prevalence ratio of clinical characteristics due to self-report of psychological distress in the academic community of a public nursing college from June 4 to September 3, 2020, Rio de Janeiro, Brazil, $2020(\mathrm{~N}=477)$

\begin{tabular}{|c|c|c|c|c|}
\hline Variables & $\mathbf{n}$ & n (\%) & PR (95\%Cl) & $\begin{array}{c}p \\
\text { value }\end{array}$ \\
\hline Group of risk & 477 & & & \\
\hline No & 275 & $43(15.64)$ & Reference & - \\
\hline Yes & 202 & $49(24.26)$ & $1.55(1.07-2.24)$ & 0.019 \\
\hline Family member in a risk group & 477 & & & \\
\hline No & 173 & $26(15.03)$ & Reference & - \\
\hline Yes & 304 & $66(21.71)$ & $1.44(0.95-2.18)$ & 0.082 \\
\hline Testing for COVID-19 & 477 & & & \\
\hline No & 358 & $65(18.16)$ & Reference & - \\
\hline Yes & 119 & $27(22.69)$ & $1.25(0.84-1.86)$ & 0.273 \\
\hline Testing positive for COVID-19 & 116 & & & \\
\hline No & 80 & $21(26.25)$ & Reference & - \\
\hline Yes & 36 & $3(16.67)$ & $0.57(0.27-1.21)$ & 0.143 \\
\hline Positive contact for COVID-19 & 477 & & & \\
\hline No & 288 & $53(18.40)$ & Reference & - \\
\hline Yes & 189 & $39(20.63)$ & $1.12(0.77-1.62)$ & 0.545 \\
\hline Clinical manifestation of FLS * & 477 & & & \\
\hline No & 97 & $27(27.84)$ & Reference & - \\
\hline Yes & 380 & $65(17.11)$ & $0.61(0.42-0.91)$ & 0.014 \\
\hline Clinical manifestation of SRAG $†$ & 477 & & & \\
\hline No & 451 & $84(18.63)$ & Reference & - \\
\hline Yes & 26 & $8(30.77)$ & $1.65(0.90-3.04)$ & 0.106 \\
\hline
\end{tabular}

The distribution and crude PR among the characteristics of social distancing, home environment and psychological distress assessments are presented in Table 3. It is observed that the presence of 
moderate and intense feelings of loneliness ( $p$ value $<0.001$ ), the regular, bad or very bad assessment of the home environment $(p$ value $<0.001$ ) and the presence of history of violence at home $p$ value 0.001$)$ and at the present time ( $p$ value $<0.001)$ were factors associated with psychological distress of students and workers.

Table 3 - Distribution and crude prevalence ratio of social distancing characteristics and the home environment due to self-report of psychological distress in the academic community of a public nursing college from June 4 to September 3, 2020, Rio de Janeiro, Brazil, 2020 ( $N=477)$

\begin{tabular}{lcccc}
\hline Variables & $\mathbf{n}$ & $\mathbf{n}(\mathbf{\%})$ & PR (95\%Cl) & $\mathbf{p}$ value \\
\hline Received/made visits & 477 & & & \\
$\quad$ No & 271 & $56(20.66)$ & Reference & - \\
$\quad$ Yes & 206 & $36(17.48)$ & $0.84(0.58-1.23)$ & 0.385 \\
Feeling of loneliness & 477 & & & \\
$\quad$ Minimal/mild & 394 & $56(14.21)$ & Reference & - \\
$\quad$ Moderate/intense & 83 & $36(43.37)$ & $3.05(2.16-4.31)$ & $<\mathbf{0 . 0 0 1}$ \\
Family atmosphere & 477 & & & \\
$\quad$ Excellent/good & 326 & $36(11.04)$ & Reference & - \\
$\quad$ Regular/bad/very bad & 151 & $56(37.09)$ & $3.35(2.31-4.87)<0.001$ \\
History of family violence & 455 & & & \\
$\quad$ No & 423 & $71(16.78)$ & Reference & - \\
$\quad$ Yes & 32 & $12(37.50)$ & $2.23(1.36-3.67)$ & 0.001 \\
Current family violence & 466 & & & \\
$\quad$ No & 453 & $82(18.10)$ & Reference & - \\
$\quad$ Yes & 13 & $6(46.15)$ & $2.55(1.37-4.74)$ & 0.003 \\
\hline
\end{tabular}

Table 4 - Poisson's final regression model due to self-report of psychological distress in the academic community of a public nursing college from June 4 to September 3, 2020, Rio de Janeiro, Brazil, 2020 ( $N=477)$

\begin{tabular}{|c|c|c|}
\hline Variables & Adjusted PR (95\%Cl) & $p$ value \\
\hline \multicolumn{3}{|l|}{ Testing for COVID-19 } \\
\hline No & Reference & - \\
\hline Yes & $1.55(1.05-2.29)$ & 0.026 \\
\hline \multicolumn{3}{|l|}{ Group of risk } \\
\hline No & Reference & - \\
\hline Yes & $1.71(1.17-2.50)$ & 0.005 \\
\hline \multicolumn{3}{|l|}{ Current family violence } \\
\hline No & Reference & - \\
\hline Yes & $2.21(1.26-3.87)$ & 0.005 \\
\hline \multicolumn{3}{|l|}{ Feeling of loneliness } \\
\hline Minimal/mild & Reference & - \\
\hline Moderate/intense & $2.64(1.79-3.90)$ & $<0.001$ \\
\hline \multicolumn{3}{|l|}{ Family atmosphere } \\
\hline Excellent/good & Reference & - \\
\hline Regular/bad/bad & $3.10(2.06-4.67)$ & $<0.001$ \\
\hline
\end{tabular}

Table 4 presents the final model of multiple regression. having five associated factors and effect of at least $55 \%$ on the prevalence of psychological distress ( $p$ value $<0.05$ ). The lowest effects were observed in disease-related variables, such as testing for COVID-19 (PR 1.55; $p$-value 0.026) and belonging to the risk group (PR 1.71; $p$ value 0.005 ). Regarding the "home environment" group variables, it was observed that regular, bad or very bad perception of family and home atmospheres (PR 3.10; $p$ value $<0.001$ ), moderate or severe feelings of loneliness (PR 2.65; $p$ value $<0.001$ ) and having suffered family violence during the pandemic period (PR 2.21; $p$ value 0.005 ) were factors associated with psychological distress.

\section{DISCUSSION}

The estimation of the COVID-19 pandemic effects on people's mental health has been a recurring theme in current literature, while there is some consensus in stating that the pandemic has produced marks that will be imprinted in the history of this generation, especially due to the high occurrences of depressive, anxious and stressful syndromes ${ }^{(4,18)}$. However, there are still few investigations that focus more systematically on school populations and university environments.

In Brazil, this manuscript is the first to estimate the prevalence of psychological distress in students and workers in higher education in the health field, more specifically in nursing, whose prevalence was $19.29 \%$. This result is compatible with the estimated prevalence in Spain ${ }^{(19)}$, Bangladesh ${ }^{(20)}$ and China ${ }^{(21)}$, which vary between $15 \%$ and $34.19 \%$ for depressive, anxious and stress disorders in students and university workers. Research carried out with students in the context of nursing also goes in the direction of demonstrating moderate stress level $\mathrm{s}^{(22)}$, in line with the findings of investigations among academics from other fields of health ${ }^{(23)}$.

However, it is necessary to be parsimony in the comparison of these findings due to the different forms of measurement between the surveys. While the international community has been concerned with classifying distress in mental disorders, this study was based on feelings perceived by the subjects themselves, i.e., on the self-report of psychological distress.

Psychological distress envisioned in an etiological or psychopathological regime is commonplace for investigations in this field, as are the international studies developed during the pandemic. However, it is possible to represent it through its multiple expressions in people's daily lives, whether they are clinical or not. Understanding that psychological distress is a product and also a producer of subjectivity, subjects can express their malaise in the form of demands, complaints or requests for help ${ }^{(24)}$, which are subject to measurement.

Considering the diversity of manifestations of these demands, a way to identify them is the item that investigated the outcome of this research (e.g., Do you feel that you are in distress or in need of professional support?). From this place of observation, it is possible to understand other factors associated with distress and which have been little observed in more traditional research regimes. Regardless of sociodemographic variables, two groups of factors associated with distress were identified: those linked to the clinic of COVID-19 and those related to family and home dynamics.

Specifically about clinical variables, such as the diagnosis and belonging to risk groups for COVID-19, it is understood that distress can be strongly linked to fear. The meanings of finitude commonly attributed to health risk situations are based on years of academic accumulation ${ }^{(25)}$. In this sense, it is coherent to think that the epidemiological setting, with many deaths of health professionals and people close to students and university workers, can generate fear, which can appear as anguish and distress. A similar result was found in a survey of Chinese university students, signaling the fear of infection as an element associated with anxiety ${ }^{(21)}$.

Additionally, it should be considered that the pandemic has introduced new stressors in social life. In addition to the fear of contracting the disease and the uncertainties about the future 
itself ${ }^{(12)}$, the fraying of social relations, the virtualization of life, the economic tension and the impacts generated by the confinement during the quarantine must be included in analytical models. A study carried out with 1,593 participants at the epicenter of the epidemic in China, in Hubei province, detected a higher prevalence of anxiety (12.9\%) and depression (22.4\%) in people affected by the quarantine, when compared with unaffected people ${ }^{(26)}$. A similar study, conducted in Chingling province, identified even higher prevalence of anxiety (35.1\%), while depressive symptoms (20.1\%) were relatively close to those found in $\mathrm{Hubei}^{(27)}$.

Although the quarantine is not a determining factor for the manifestation of the feeling of loneliness, studies show that it is undeniable that its deepening as a result of $i^{(11,28)}$. A study conducted with 6,186 participants in the United States, with monthly measurements between April and September 2020, identified higher scores of feelings of loneliness, which increased with time among Americans who reported being in lockdown ${ }^{(28)}$. The prospect of worsening of these feelings during the quarantine is confirmed by Bu's study ${ }^{(11)}$, whose findings suggest the equivalence of risk factors between the time before COVID-19 and the current one. Young, low-income female adults who live alone and live in urban areas are at greater risk of developing more severe levels of loneliness. Furthermore, when taking as a basis that these feelings are considered antecedents of depressive situations and predictors of lethal injuries, such as suicide attempt ${ }^{(10)}$, it seems urgent to build approximation practices that facilitate the dialogue between the various actors that make up the environment university. Early identification of distress situations by peers can be a potent strategy in the management of cases, with greater chances of implementing care practices in a timely manner.

Adding to the fact that the worst assessments on the family atmosphere increase the strength of association with psychological distress in the sample. Although the idealization of a welcoming family and the association of the home as a safe place are common, it is important to reflect that a significant part of violence against children, women and older adults occurs precisely by relatives and in the home environment ${ }^{(29)}$. It is a consensus that violent events increased during the pandemic, increasing fatalities ${ }^{(30)}$. With this, the construction of a common sense of a protective family also seems to be an important element for the systematic denial and concealment of violations, and this deserves to be closely monitored by training environments, reinforcing their role and political engagement in these contexts.

If, on the one hand, the distance measures and the interruption of face-to-face classes in schools and universities were important resources to contain the COVID-19 progression curve, on the other hand, it was clear how much more people became more exposed to the environments adverse to the promotion of psychosocial and physical health. Considering the dialectical configuration that is established in the relationship between actions that aim to reduce agglomerations, but which, at the same time, produce psychological distress through social distancing at home, it seems essential to set up work groups involving the school, social structures and, fundamentally, the subjects themselves, for the formulation of solidary strategies to face the pandemic impacts. Therefore, it is essential that the school, as a powerful socialization space to unveil situations commonly censored by the home environment, becomes co-responsible for this phenomenon, creating spaces for production of care and protection of life.

\section{Study limitations}

Despite the relevance of these data, it is essential that their interpretation be carried out in light of their limitations. The first and perhaps most important is the fact that psychological distress was assessed through self-report, whereas this estimation tends to capture the most serious cases and, therefore, perceived (or potentially perceived) by subjects. On the other hand, it is possible to have cases of psychological distress not yet recognized, due to fear, shame or ignorance of its forms of manifestation. In this sense, specific and validated instruments for capturing this phenomenon should be used in future investigations on the subject. Even with all the investment in multiple forms of recruitment during data collection, convenience sampling may have produced selection bias. The presence of this bias may have imputed lower chances of response by people in greater vulnerability, such as students and workers without access to the internet.

\section{Contributions for nursing}

Once the scarcity of research that addresses the theme of this study is pointed out, it is believed that the data produced here may contribute to the promotion of reflections on mental health during this and eventually other major health emergencies. The data point to the need to reinforce the School's place, which also produces the recognition of students' and workers' human needs, driving the construction of protection and care policies in mental health.

\section{CONCLUSIONS}

The high magnitude of psychological distress among students and workers was observed, compatible with similar investigations in other settings. The study revealed that the potential expressions of fear of COVID-19, associated with diagnosis and belonging to groups at risk, perceptions about the family atmosphere, violence and the feeling of loneliness have produced psychological distress during the pandemic. The recognition of these factors calls on schools, especially those dedicated to training health professionals, to occupy a place in early identification of distress and its causes in the community for the formulation of care and protection strategies.

\section{REFERENCES}

1. Rafael RMR, Neto M, Carvalho MMB, Leal David HMS, Acioli S, Araujo Faria MG. Epidemiology, public policies and covid-19 pandemics in Brazil: what can we expect? Rev Enferm. 2020;28:1-6. https://doi.org/10.12957/REUERJ.2020.49570 
2. Lima LD, Pereira AMM, Machado CV. Crisis, conditioning factors, and challenges in the coordination of Brazil's federative State in the context of COVID-19. Cad Saúde Publica. 2020;36. https://doi.org/10.1590/0102-311X00185220

3. Husky MM, Kovess-Masfety V, Swendsen JD. Stress and anxiety among university students in France during Covid-19 mandatory confinement. Compr Psychiatry. 2020;102:152191. https://doi.org/10.1016/j.comppsych.2020.152191

4. Kontoangelos K, Economou M, Papageorgiou C. Mental health effects of COVID-19 pandemia: A review of clinical and psychological traits. Psychiatry Investig. 2020;17:491-505. https://doi.org/10.30773/pi.2020.0161

5. Xiong J, Lipsitz O, Nasri F, Lui LMW, Gill H, Phan L, et al. Impact of COVID-19 pandemic on mental health in the general population: a systematic review. J Affect Disord. 2020;277:55-64. https://doi.org/10.1016/j.jad.2020.08.001।

6. Portugal FB, Campos MR, Gonçalves DA, Mari JJ, Fortes SLCL. Qualidade de vida em pacientes da atenção primária Do Rio de Janeiro e São Paulo, Brasil: Associações com eventos de vida produtores de estresse e saúde mental. Cienc e Saude Coletiva. 2016;21:497-508. https://doi. org/10.1590/1413-81232015212.20032015

7. Psíquico S, La EN, Manique M, Crivelatti B, Durman S, Hofstatter LM. Sofrimento psíquico na adolescência. Texto Contexto Enferm. 2006;15(spe):64-70. https://doi.org/10.1590/S0104-070706000500007

8. Oliveira AFC, Teixeira ER, Athanázio AR, Soares RS. Psychic suffering and psychodynamics in the nurse's work environment: an integrative review. O Braz J Nurs. 2020;19. https://doi.org/10.17665/1676-4285.20206353

9. Rotelli F, Leonardis O, Mauri D. Desinstitucionalização, uma outra via. A reforma psiquiátrica italiana no contexto da europa ocidental e dos "países avançados". Desinstitucionalização. 2nd ed., São Paulo: Hucitec; 2019, p. 17-60.

10. Killgore WDS, Cloonan SA, Taylor EC, Miller MA, Dailey NS. Three months of loneliness during the COVID-19 lockdown. Psychiatry Res. 2020;293:1-2. https://doi.org/10.1016/j.psychres.2020.113392

11. Bu F, Steptoe A, Fancourt D. Who is lonely in lockdown? cross-cohort analyses of predictors of loneliness before and during the COVID-19 pandemic. Public Health. 2020;186:31-4. https://doi.org/10.1016/j.puhe.2020.06.036

12. Barros MBA, Lima MG, Malta DC, Szwarcwald CL, Azevedo RCS, Romero D, et al. Relato de tristeza/depressão, nervosismo/ansiedade e problemas de sono na população adulta brasileira durante a pandemia de COVID-19. Epidemiol Serv Saude. 2020;29:e2020427. https://doi. org/10.1590/s1679-49742020000400018

13. Von Elm E, Altman DG, Egger M, Pocock SJ, Gøtzsche PC, Vandenbroucke JP. The Strengthening the Reporting of Observational Studies in Epidemiology (STROBE) statement: guidelines for reporting observational studies. PLoS Med. 2007;4:1623-7. Available from: https://doi. org/10.1371/journal.pmed.0040296

14. Eysenbach G. Improving the quality of web surveys: the Checklist for Reporting Results of Internet E-Surveys (CHERRIES). J Med Internet Res. 2004;6:1-6. https://doi.org/10.2196/jmir.6.3.e34

15. Ministério da Saúde (BR). Protocolo de Manejo Clínico da Covid-19 na Atenção Especializada. Brasília: MS; 2020.

16. Barroso SM, Andrade VS, Midgett AH, Carvalho RGN. Evidências de validade da escala Brasileira de Solidão UCLA. J Bras Psiquiatr. 2016;65:68-75. https://doi.org/10.1590/0047-2085000000105

17. Barroso SM, Andrade VS, Oliveira NR. Escala Brasileira de Solidão: análises de resposta ao item e definição dos pontos de corte. J Bras Psiquiatr. 2016;65:76-81. https://doi.org/10.1590/0047-2085000000106

18. Moreira WC, Sousa AR, Nóbrega MPSS. Mental illness in the general population and health professionals during covid-19: a scoping review. Texto Contexto Enferm. 2020;29:e20200215. https://doi.org/10.1590/1980-265x-tce-2020-0215

19. Odriozola-González P, Planchuelo-Gómez Á, Irurtia MJ, Luis-García R. Psychological effects of the COVID-19 outbreak and lockdown among students and workers of a Spanish university. Psychiatry Res. 2020;290. https://doi.org/10.1016/j.psychres.2020.113108

20. Khan AH, Sultana MS, Hossain S, Hasan MT, Ahmed HU, Sikder MT. The impact of COVID-19 pandemic on mental health \& wellbeing among homequarantined Bangladeshi students: a cross-sectional pilot study. J Affect Disord. 2020;277:121-8. https://doi.org/10.1016/j.jad.2020.07.135

21. Cao W, Fang Z, Hou G, Han M, Xu X, Dong J, et al. The psychological impact of the COVID-19 epidemic on college students in China. Psychiatry Res. 2020;287:1-5. https://doi.org/10.1016/j.psychres.2020.112934

22. Aslan $\mathrm{H}$, Pekince H. Nursing students' views on the COVID-19 pandemic and their perceived stress levels. Perspect Psychiatr Care. 2020;57(2):695-701. https://doi.org/10.1111/ppc.12597

23. Abdulghani HM, Sattar K, Ahmad T, Akram A. Association of COVID-19 pandemic with undergraduate medical students' perceived stress and coping. Psychol Res Behav Manag. 2020;13:871-81. https://doi.org/10.2147/PRBM.S276938

24. Dunker CIL. Formas de apresentação do sofrimento psíquico: alguns tipos clínicos no Brasil contemporâneo. Rev Subjetiv. 2004;4:94-111. https://doi.org/10.5020/23590777.4.1.94

25. Santos R, Mohr AM. A (de)vida angústia de morte: considerações a partir da filosofia e da psicanálise. Nat Humana [Internet] 2018 [cited 2020 Dec 03];20:169-87. Available from: http://pepsic.bvsalud.org/pdf/nh/v20n1/v20n1a11.pdf

26. Lei L, Huang X, Zhang S, Yang J, Yang L, Xu M. Comparison of prevalence and associated factors of anxiety and depression among people affected by versus people unaffected by quarantine during the COVID-19 Epidemic in Southwestern China. Med Sci Monit. 2020;26:1-12. https://doi.org/10.12659/MSM.924609 
27. Huang Y, Zhao N. Generalized anxiety disorder, depressive symptoms and sleep quality during COVID-19 outbreak in China: a web-based cross-sectional survey. Psychiatry Res. 2020;288:112954. https://doi.org/10.1016/j.psychres.2020.112954

28. Killgore WDS, Cloonan SA, Taylor EC, Lucas DA, Dailey NS. Loneliness during the first half-year of COVID-19 Lockdowns. Psychiatry Res. 2020;294:113551. https://doi.org/10.1016/j.psychres.2020.113551

29. Marques ES, Moraes CL, Hasselmann MH, Deslandes SF, Reichenheim ME. Violence against women, children, and adolescents during the COVID-19 pandemic: overview, contributing factors, and mitigating measures. Cad Saude Publica. 2020;36. https://doi. org/10.1590/0102-311X00074420

30. Campbell AM. An increasing risk of family violence during the Covid-19 pandemic: strengthening community collaborations to save lives. Forensic Sci Int Reports. 2020;2:100089. https://doi.org/10.1016/j.fsir.2020.100089 